\title{
O desafio de pesquisar a educação infantil: limites e possibilidades
}

\section{The challenge of researching early childhood education: limits and possibilities}

\section{Evelise Maria Labatut Portilho ${ }^{[a]}$, Hilda Maria Zanetti Heller de Mattos ${ }^{[b]}$, Juliana Boff Aramayo Cruz ${ }^{[c]}$}

[a] Doutora em Educação, professora titular da Pontifícia Universidade Católica do Paraná (PUCPR), Curitiba, PR, Brasil, e-mail: evelisep@onda.com.br

${ }^{[b]}$ Mestre em Educação, Pontifícia Universidade Católica do Paraná (PUCPR), Curitiba, PR, Brasil, e-mail: hildaheller@gmail.com

[c] Mestre em Educação, Pontifícia Universidade Católica do Paraná (PUCPR), Curitiba, PR, Brasil, e-mail: juboffac@gmail.com

\section{Resumo}

O presente artigo relata os resultados da pesquisa "Aprendizagem e conhecimento na ação educativa", de uma escola de educação infantil da rede privada na cidade de Curitiba, PR. O ensino infantil é a etapa da educação em que as crianças são sujeitos ativos de sua aprendizagem e desenvolvimento, protagonizando a construção do conhecimento. Por entender que a professora desempenha importante papel nessa etapa, decidiu-se pesquisar a representação profissional e social dessa professora, tendo como objetivo fazê-la 
perceber-se como profissional do ensino atuando como pesquisadora de sua prática educativa. Optou-se por utilizar como instrumentos de pesquisa: entrevistas com as professoras, com os pais de alunos e com funcionários da escola, diários dos alunos e das professoras, observação da sala de aula e do ambiente educativo, Questionário Honey-Alonso de Estilos de Aprendizagem, Inventário Portilho-Beltrami de Estilos de Aprendizagem com as crianças e encontros reflexivos com as professoras. Os dados indicam que a representação profissional que as professoras têm de si mesmas está pautada no cuidado meramente assistencialista, denotando a dicotomia do binômio educar/cuidar. Por outro lado, a representação social que a comunidade tem da professora da educação infantil já apresenta uma mudança, com ascendência significativa da formação docente associada ao cuidado como atitude fundante do ser humano. A formação da professora como pesquisadora ainda apresenta desafios, sendo necessário desenvolver a reflexividade na prática pedagógica cotidiana.

Palavras-chave: Educação infantil. Aprendizagem. Representação profissional e social.

\section{Abstract}

The present article reports the initial data of the pilot research "Learning and knowledge in the educational action" based on the results gotten from a private early childhood education school in Curitiba, PR. the early childhood education is a part in the educational process in which children take active part in their own learning and development, starring the building of knowledge. Understanding that the teacher plays an important role in this stage of the child's development and learning, it was decided to study the social and professional responsibility of these teachers, intending to make them perceive themselves as professionals of education, acting as researchers of their own educational practice. It was chosen to use as research methods: interviews with teachers, student's parents and school staff; children's and teachers' diaries; observation of school educational environment; Honey-Alonso's Learning Styles Questionnaire; Portilho-Beltrami Inventory; and also reports about reflexive meetings during the process of mentioned methods implementation. The data indicate that the professional view those teachers have of themselves is based in the merely assistant care, revealing the dichotomy between teach/take care. On the other hand, the social idea that the community has of those teachers has already presented a change, with the significant increase in teacher's education (graduation) associated with 
the caring as an inherent attitude of human being. The development of the teacher as a researcher is still a challenge, being necessary to develop the reflexive practice in the daily teaching practice.

Keywords: Early childhood education. Learning. Professional and social representation.

\section{Introdução}

A educação infantil é o espaço privilegiado em que a criança aprende a se conhecer e a respeitar o próximo, a pensar sobre sua aprendizagem refletindo sobre o mundo que a rodeia. Nessa etapa da educação, as crianças são sujeitos ativos de sua aprendizagem e desenvolvimento, protagonistas na construção do conhecimento. A criança já é um ser em si, constituída social e historicamente, capaz de expressar ideias e sentimentos, reproduzindo e produzindo a cultura na qual está inserida, por meio das mais diferentes linguagens.

Partindo desse pressuposto, a professora de educação infantil desempenha importante papel de mediadora da aprendizagem e do desenvolvimento dessa criança. Para tanto, é necessário que essa docente se perceba como profissional da educação, atuando como pesquisadora de sua prática educativa.

Este artigo decorre da pesquisa "Aprendizagem e conhecimento na ação educativa", e relata a etapa inicial realizada numa escola da rede privada na cidade de Curitiba, PR, Brasil, no fim do ano de 2009.

Os objetivos deste estudo são identificar a representação profissional que a professora de educação infantil tem de si mesma, bem como a representação social que a comunidade educativa possui dela; e possibilitar a sua formação como pesquisadora de sua prática educativa.

A seguir serão apresentados os principais resultados extraídos dos instrumentos elaborados e aplicados, como as entrevistas semiestruturadas com sete professoras, as entrevistas semiestruturadas com 
a comunidade educativa (quatro funcionários da área administrativa), os questionários com 22 pais, os diários das professoras e 93 alunos, e o registro dos seis encontros reflexivos realizados com elas. Os temas selecionados para esses encontros quinzenais com as professoras foram sensibilização, identidade, ambiente educativo, estilos de aprendizagem, representação pessoal e social da professora, e avaliação do processo.

Com o propósito de promover o processo de reflexão grupal, foram organizados seis encontros de duas horas cada, pensados metodologicamente para favorecer a discussão entre os membros do grupo docente, sempre mediados por quatro pesquisadoras, duas delas conduzindo a vivência e as outras duas no registro das observações temáticas e dinâmicas. Cada encontro iniciava com os participantes em círculo, havendo um momento de sensibilização para o tema proposto, seguido da fundamentação teórica e vivências. Para a reelaboração do tema acontecia uma "roda de conversa", com consignas preestabelecidas. Como fechamento do encontro, era proposta uma tarefa a ser realizada na quinzena seguinte, assim como o momento de avaliação do encontro.

Foi dessa maneira que o grupo de pesquisadoras entendeu e praticou o processo de pesquisa-ação numa perspectiva reflexiva.

\section{A representação profissional e social da professora de educação infantil}

Antes de abordar a representação social, é mister esclarecer o sentido da palavra representação, assim como fundamentá-la teoricamente. Segundo o dicionário Houaiss (2008), representação compreende a "ideia ou imagem que concebemos do mundo ou de algo". Então, representar algo significa trazer à consciência coisas ausentes e, por isso, possui um caráter simbólico. Moscovici (apud SPINK, 1995, p. 33) complementa dizendo que "representar uma coisa [...] não é com efeito simplesmente duplicá-la, repeti-la ou reproduzi-la; é reconstituí-la, retocá-la, modificarlhe o texto". Dessa forma, a representação envolve a compreensão, a leitura que o pensamento social possui de uma determinada realidade. 
Nesse trabalho toma-se por base o conceito de representação social dado por Moscovici (2009, p. 21):

um sistema de valores, ideias e práticas, com uma dupla função: primeiro, estabelecer uma ordem que possibilitará às pessoas orientarse em seu mundo material e social e controlá-lo; e, em segundo lugar, possibilitar que a comunicação seja possível entre os membros de uma comunidade, fornecendo-lhes um código para nomear e classificar, sem ambiguidade, os vários aspectos de seu mundo e da sua história individual e social.

Como é possível observar, a representação social elaborada por um determinado grupo sobre um objeto social relevante é uma forma de conhecimento, apresentando importância por direcionar comportamentos e facilitar a comunicação entre as pessoas que vivem essas representações no grupo.

Denise Jodelet, colega de Moscovici, define a representação social como uma "forma de conhecimento prático [savoir] conectando um sujeito a um objeto" (JODELET, 1989 apud MOSCOVICI, 2009, p. 21).

As representações sociais estão presentes desde o início da vida, e a criança insere-se em uma sociedade estruturada por essas representações. A influência destas no desenvolvimento e na aprendizagem do sujeito ocorre desde cedo, estando presente na maneira como a criança percebe e interage com e no mundo.

Com relação às professoras, o caminho percorrido para a construção de suas representações profissionais e sociais é o mesmo. Elas estabelecem contato com as representações que lhes são apresentadas, com o objetivo de fazer parte do seu grupo social. Sendo assim, é urgente que essa professora tome consciência de que não é só produto, mas também produtora de representações.

Para que fosse possível identificar a representação profissional que a própria professora tem de si, foram analisadas as entrevistas e os encontros reflexivos.

Em relação à representação profissional que as professoras possuem de si, 28,5\% delas apresentam a educação infantil como opção de 
trabalho por terem um "tal sentimento" que tende a apresentar a docência como algo inato.

O primeiro é afinidade. Eu acho que tem jeito para lidar com a criança pequena, jeito para lidar com a criança grande. Tem que ter. Tem que gostar, tem que ter jeito. Não é porque eles são mais maduros que é mais fácil. A meu ver, não é. É bem mais gostoso pela afinidade, pelo contato, pela sintonia (PROFESSORA C).

Acredito que eu já nasci, porque eu lembro que só brincava de escolinha. E, mesmo assim, o que me encanta é a sinceridade dos pequenos (PROFESSORA D).

Já 28,5\% apresentam a docência como uma atividade que vai ao encontro de seu perfil, isto é, possuem habilidades e características pessoais adequadas às crianças da educação infantil.

Porque eu acho que tenho mais facilidade em trabalhar com crianças um pouco menores [...] até essa faixa etária (PROFESSORA A).

Já trabalhei como auxiliar do fundamental aqui na escola. Eu acho que no momento é o que tem o meu perfil, o que eu gosto é a educação infantil (PROFESSORA G).

Ao atribuir a docência à própria personalidade, percebe-se que as professoras desconhecem o fato de que a personalidade não é algo inato, e sim construído durante a vida em interação com outras pessoas e perante diversas representações que vivenciam em seu cotidiano.

Em relação aos aspectos necessários para ser professora da educação infantil, a maioria das professoras, durante as entrevistas, percebe em si mesma características relacionadas ao cuidado, tais como afeto, paciência, sensibilidade e dom.

Cuidado! A maior característica minha é o cuidado com eles, acho que é isso que a educação infantil requer [...] assim [...] a prioridade (PROFESSORA A). 
O cuidado, atenção com tudo que acontece à minha volta, ajuda com as crianças, o carinho (PROFESSORA B).

Afeto, sensibilidade, paciência e acreditar na capacidade de cada criança, mesmo com suas limitações (PROFESSORA E).

Atenção, percepção, um olhar diferente, um gostar de ensinar, a paciência do dia a dia... Porque com os menores não é aquela coisa: fez e já tem uma correspondência, já tem um resultado certo... É um processo. Eu acredito que é um dom. Eu não consigo entender, algumas coisas a gente aprende, algumas coisas vêm da gente, não tem como ensinar, como passar (PROFESSORA, C).

O cuidado mencionado pelas docentes refere-se ao aspecto assistencialista e não a uma atitude constituinte do ser humano, como defende Martin Heidegger (apud BOFF, 1999, p. 34): "do ponto de vista existencial, o cuidado se acha a priori, antes de toda atitude e situação do ser humano, o que sempre significa dizer que ele se acha em toda atitude e situação de fato". Dessa maneira, quer dizer que o cuidado é uma dimensão ontológica do ser humano, está presente na essência do humano e, por isso, é condição de nossa humanidade.

Quando as professoras se referem às características que possuem, se distanciam da perspectiva de cuidado defendida pelo autor, porque, como corrobora Boff (1999, p. 33), "cuidar é mais que um ato; é uma atitude. Portanto, abrange mais que um momento de atenção, de zelo e de desvelo. Representa uma atitude de ocupação, preocupação, responsabilização e de envolvimento afetivo com o outro". Dessa maneira, percebe-se na fala das docentes uma concepção de criança e infância como algo incompleto, a formar-se.

Porém, analisando as observações feitas em sala de aula, percebem-se em apenas $14,2 \%$ das professoras a preocupação e a atenção aos aspectos educativos, aqueles relacionados à aprendizagem formal e sistematizada, apesar de não serem citados por elas na entrevista.

$\mathrm{Na}$ observação da sala da professora $\mathrm{F}$, durante o trabalho com imagens em livros, ela introduziu o tema a ser trabalhado a partir do 
questionamento com os alunos acerca do que sabiam sobre a imagem. Estimulou a criatividade e a imaginação solicitando que cada um criasse um nome para os personagens das imagens. Esse dado revela que a professora demonstra ter conhecimento da necessidade de estimular a criatividade e a imaginação em crianças da educação infantil.

Outro aspecto que chama a atenção na entrevista com as professoras é o fato de não aparecer nas respostas a educação formal como necessária à sua formação, reforçando a ideia de que o conhecimento específico da educação infantil e a formação ficam relegados a um segundo plano. Como afirma Kramer (2005), o binômio educar/cuidar vem se tornando uma dicotomia, isto é, em vez de serem aspectos complementares e indissociáveis, ainda permanecem na maioria das professoras como oposição: ou cuida-se ou educa-se.

A partir dessa constatação, percebeu-se a necessidade de reforçar a fundamentação teórica nos encontros reflexivos, como foi o caso da inclusão do tema Cuidado por meio da contação de história do Mito do Cuidado. Da mesma maneira, constatou-se que as professoras não tinham conhecimento do que significa representação profissional e social, sendo também inserido esse tema em um dos encontros.

Além da fundamentação teórica sobre representação, foi proposto que as próprias professoras pesquisassem como seus alunos as percebiam, por meio do "desenho da professora". No Maternal, poucos alunos apresentaram tentativa de representação da figura humana, o que é esperado para a idade. Já nas turmas de Jardim I, II e III, as professoras aparecem representadas de várias maneiras: estáticas, andando, sorrindo, brincando, enfeitadas com flores (como representado na Figura 1A), fazendo atividades. Os alunos também se incluem em alguns desenhos, e, como demonstram as Figuras 1B e 1C, retratando não somente a professora, mas também a criança, parte da relação pedagógica ocorrida em sala de aula.

A representação profissional da professora também foi percebida nas observações de sala e no ambiente educativo como um todo, onde se constatou que muito além da proposta pedagógica da escola revelada no ambiente está a personalização que cada professora imprime em sua classe. 

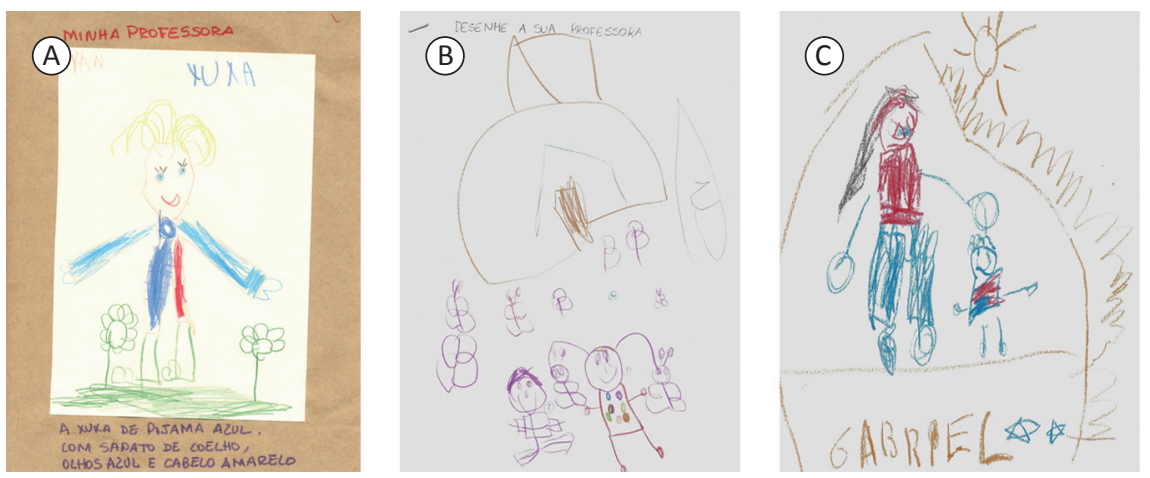

Figura 1 - Desenhos da professora realizados pelos alunos (crianças de 4 e 5 anos) Fonte: Imagens obtidas do material produzido pelas crianças.

Como exemplo, em uma das salas, a professora demonstra a preocupação em criar espaços diferentes para a roda de conversa com as crianças e para o trabalho gráfico, deixando os materiais ao alcance delas, estimulando, assim, a autonomia.

$\mathrm{Na}$ representação social apresentada pela comunidade escolar constataram-se a importância e a necessidade da formação específica das professoras para trabalharem na educação infantil, bem como do conhecimento acerca do desenvolvimento infantil. Nas respostas da família e dos funcionários, isso ficou evidenciado.

Principalmente a formação e amor pela profissão (PAIS B).

A idade e estado civil considero irrelevante, porém a formação deve ser específica, na área, logicamente, e com conhecimentos maiores no comportamento da faixa etária em questão (PAIS L).

Formação é o ponto mais fundamental (PAIS Q).

O importante para trabalhar com crianças é a formação e interesse no desenvolvimento infantil, ter tato e ao mesmo tempo pulso para desenvolver 
as atividades propostas com seriedade... mas também com a sensibilidade necessária (PAIS U).

Boa formação (de qualidade e especializada)

Dedicação à escola

Compreensão das etapas do desenvolvimento infantil e respeito por elas

Conhecimento de bons métodos de ensino (PAIS W).

Formação: curso superior e procurar se profissionalizar. Importante ser paciente, organização (FUNCIONÁRIO C).

O Plano Nacional de Educação (PNE) de 2001 reforça em seu texto que:

a formação dos profissionais da educação infantil merecerá uma atenção especial, dada a relevância de sua atuação como mediadores no processo de desenvolvimento e aprendizagem. A qualificação específica para atuar na faixa de zero a seis anos inclui o conhecimento das bases científicas do desenvolvimento da criança, da produção de aprendizagens e a habilidade de reflexão sobre a prática, de sorte que esta se torne, cada vez mais, fonte de novos conhecimentos e habilidades na educação das crianças (BRASIL, 2001a).

Analogamente, Kramer (2002, p. 129) propõe que "a educação da criança de 0 a 6 anos tem o papel de valorizar os conhecimentos que as crianças possuem e garantir a aquisição de novos conhecimentos, mas, para tanto, requer um profissional que reconheça as características da infância”. Reconhecer as características da infância pressupõe o conhecimento do desenvolvimento infantil, como relatado pelo PNE (BRASIL, 2001a) e por alguns pais ao responderem o questionário.

Afora a formação das professoras, quase metade dos pais destaca a importância das características pessoais das professoras como o amor, o carinho, a dedicação e a paciência com os alunos.

Disponibilidade, amor, paciência, energia, organização, ânimo e conhecimento profissional (PAIS E). 
Formação (com continuidade), dedicação, vontade, vocação, gosto, bom senso, bons valores, carinho, amor, respeito, sensibilidade (PAIS A).

Paciência, responsabilidade, dedicação, compreensão do desenvolvimento infantil, respeito pelas diferenças (PAIS O).

Os pais também retratam nas suas expectativas em relação às professoras a ênfase na reflexão e educação como prioridade (metade dos pais), seguido do aspecto do cuidado (um quarto dos pais), ressaltando uma mudança importante na concepção da educação infantil. Passa-se de uma prática puramente assistencialista, ligada prioritariamente ao cuidado, para uma prática que associa a educação com o cuidado, tendo como concepção a ideia de que "não é possível educar sem cuidar" (KRAMER, 2005, p. 62); isto é, ao educar, no sentido pleno da palavra, a professora consequentemente tem a atitude de cuidar.

Em resumo, a representação profissional que as professoras têm de si mesmas está no cuidado meramente assistencialista, denotando a dicotomia entre educar/cuidar. Por outro lado, a representação social que a comunidade tem da professora da educação infantil já apresenta uma mudança, com ascendência significativa da formação docente associada ao cuidado como atitude fundante do ser humano.

\section{A construção da professora pesquisadora}

Diante do contexto contemporâneo, a formação de professores não contempla somente a formação inicial, mas também a formação continuada e o desenvolvimento profissional, bem como a formação em ação.

Nessa pesquisa utilizou-se a formação em ação como possibilidade de fornecer às professoras subsídios teóricos e práticos, por meio dos encontros e da aplicação de diferentes instrumentos como os diários das professoras e dos alunos, o Inventário Portilho/Beltrami de Estilos de 
Aprendizagem e a representação da professora realizada pelos alunos por meio de desenho gráfico.

O despertar do olhar investigativo, da "curiosidade epistemológica" (FREIRE, 2008) e da reflexão sobre a prática promovem o desenvolvimento da professora como pesquisadora de sua práxis e, portanto, autora e produtora de sua identidade profissional.

Nóvoa (1995, p. 25) afirma que "a formação não se constrói por acumulação (de cursos, de conhecimentos ou de técnicas), mas sim através de um trabalho de reflexividade crítica sobre as práticas e de (re)construção permanente de uma identidade profissional". O autor evidencia, anos antes, o que o Referencial Curricular Nacional ( $R C N)$ para a educação infantil brasileira aponta como meta de qualidade.

O trabalho direto com crianças pequenas exige que o professor tenha uma competência polivalente. Ser polivalente significa que ao professor cabe trabalhar com conteúdos de naturezas diversas que abrangem desde os cuidados básicos essenciais até conhecimentos específicos provenientes das diversas áreas do conhecimento. Este caráter polivalente demanda, por sua vez, uma formação bastante ampla do profissional, que deve tornar-se ele também um aprendiz, refletindo constantemente sobre sua prática, debatendo com seus pares, dialogando com as famílias e a comunidade e buscando informações necessárias para o trabalho que desenvolve. São instrumentos essenciais para a reflexão sobre a prática direta com as crianças a observação, o registro, o planejamento e a avaliação (BRASIL, 2001b, p. 41).

De acordo com o referencial, não cabe mais um professor com formação restrita ou sem formação específica para o magistério. Solicitase que, além de formação, ele tenha articulação suficiente para promover o desenvolvimento da criança em todos os aspectos: cognitivo, emocional, psicomotor e social, sem perder de vista os cuidados essenciais e a realidade social e cultural em que está inserido. Isso é ser "polivalente".

Nessa perspectiva dialética de fazer educação, o professor da educação infantil torna-se um aprendiz e desenvolve-se passo a passo 
com seus alunos porque reflete sobre a sua prática a partir da observação, registro, análise e avaliação dos dados obtidos do seu planejamento de ação docente. Então, não é isso uma pesquisa?

Os dados obtidos com a análise de $100 \%$ dos diários das professoras demonstraram que o registro realizado revela limites e possibilidades para um trabalho docente que privilegie a pesquisa. Em 57\% dos diários, as professoras descrevem sucintamente a rotina, como pode ser observado no exemplo a seguir.

Brincamos no pátio.

Lanchamos às $9 \mathrm{~h}$.

Fizemos uma roda de novidade.

Organizamos as mesas com jornal.

Fizemos obra de arte usando argila.

Criamos e demonstramos muitas coisas.

Descobrimos como deixar as bolinhas de argila bem redondas.

Criamos jogos de boliche, boneca, sofá, bolas e muitas bolinhas.

Utilizamos palitos para modelar.

Fomos brincar no pátio. Descobrimos que no teto da sala de artes possui um ninho, do pássaro sabiá.

Almoçamos todos os dias relembrando como é legal ser comportado na mesa. Conversando pouco, não derramamos comida fora do prato e mastigamos com a boca fechada. Brincamos no patiozinho (PROFESSORA A).

A descrição cronológica das ações praticadas ao longo do dia não apresenta a reflexão que se espera de um professor pesquisador. Em 14,2\% dos diários constatou-se a mesma descrição da rotina, mas com a tentativa de análise a partir da descrição de conteúdos e metodologia. No entanto, deixou-se de avaliar aquilo que foi realizado.

No segundo momento foi como compramos os produtos no mercado, com dinheiro. Então peguei várias notas, as verdadeiras e as sem valor, falei e mostrei a do dólar e da Disney (eles amaram... rs) aí exploramos de várias maneiras, fizemos contas, somamos, diminuímos, etc. (PROFESSORA C). 
Em 28,5\% dos diários perceberam-se possibilidades para continuar um trabalho de construção da professora pesquisadora, porque os relatos incluíram conteúdos, objetivos, metodologia de trabalho e reflexões sobre a prática.

Do início ao final da tarde é um descobrir de capacidades cada vez mais aprimorado, tanto da professora, quanto de alunos.

O momento da roda é onde sempre trago um gênero textual, nos possibilita fazermos reflexões sobre o tema do dia. Neste dia foi a notícia sobre a lei antifumo no jornal Gazeta do Povo. Comecei perguntando quem já tinha ouvido falar sobre este assunto e todos tinham algo a dizer, como: cigarro, perigo, fumaça, ficar doente - dores no coração, dores no pulmão, ir para o hospital, muita fumaça ruim, ficar sem nosso pai e nossa mãe. Bom, vi que já tinham muitas informações sobre a notícia, e ao final eles disseram que fumar faz mal e não é legal, pois as pessoas adoecem.

[...] fizemos uma culinária e aproveitamos para falar sobre os estados sólidos, líquidos, gasosos e pastosos. [...] uma das meninas disse: né Rô, que o que nós bebemos é líquido, eu disse que sim, aí aproveitando eu perguntei: e o que nós comemos o que será que é? Um dos meninos respondeu: é sólido, um outro disse: minha mãe disse que os ossos também é sólido, bom fomos muito longe, [...] eles trouxeram até uma garrafa de água com gás, e tudo foi aproveitado, inclusive a panela que cozinhou a batata fazendo pressão, o fogo do fogão, até o botijão de gás. [...] Esta foi nossa tarde e no final fizemos um registro coletivo (PROFESSORA F).

Ao fazer esse relato, a professora demonstrou estar atenta ao processo de aprendizagem e produção de conhecimento dos alunos, sendo ela mesma uma pesquisadora quando reflete sobre a prática e ainda faz junto com eles o registro coletivo das descobertas do dia.

Freire (2008, p. 29) assevera:

no meu entender o que há de pesquisador no professor não é uma qualidade ou uma forma de ser ou de atuar que se acrescente à de ensinar. Faz parte da natureza prática do docente a indagação, a busca, a pesquisa, o de que se precisa é que, em sua formação permanente, o professor se perceba e se assuma, porque professor, como pesquisador. 
O professor pesquisador é aquele que se percebe e se assume como protagonista no processo de aprendizagem e desenvolvimento de seus alunos.

Ainda com a preocupação de sensibilizar as professoras para a pesquisa, num dos encontros foi aplicado o questionário Honey/Alonso de Estilos de Aprendizagem, a fim de que se percebessem como aprendizes. O referido instrumento aborda quatro estilos de aprendizagem: ativo, reflexivo, teórico e pragmático. O resultado desse grupo de professoras indicou que todas se consideram reflexivas. No entanto, quando esse resultado foi comparado com a análise dos diários da professora, apenas duas, as mesmas que apresentaram nos relatos indícios de pesquisadora, revelaram no seu discurso características desse estilo.

Depois que as professoras passaram pela experiência de refletir sobre seu próprio estilo de aprendizagem, elas mesmas aplicaram o Inventário Portilho/Beltrami de Estilos de Aprendizagem nas crianças, a fim de identificar os estilos de aprendizagem de seus alunos, oportunizando mais uma vez uma situação de pesquisa.

Um último instrumento que oportunizou a prática da professora como pesquisadora foi o diário do aluno, no qual elas pediram que as crianças registrassem, por meio de desenhos ou palavras, o que a professora ensinou e o que a criança aprendeu. Nesse instrumento, podese observar o registro das atividades mais significativas para as crianças. Porém, só foi possível identificar os desenhos das crianças de 4 e 5 anos. No desenho das crianças menores, por estarem na fase da garatuja, não se conseguiu identificar o significado de cada registro, sentindo-se a necessidade da professora incluir, no momento do desenho, o relato do que a criança desenhou por meio da linguagem oral.

Logo, é fundamental que se continue insistindo na instauração de um processo reflexivo que permita ao professor, com os seus pares, por meio da pesquisa sobre a sua prática, produzir conhecimento e construirse na formação permanente, percebendo-se e assumindo sua docência, tornando-se consciente da sua prática e da sua própria inconclusão diante do conhecimento, pois, como insiste Freire (2008, p. 135-136): 
me sinto seguro porque não há razão para me envergonhar por desconhecer algo. Testemunhar a abertura aos outros, a disponibilidade curiosa à vida, a seus desafios, são saberes necessários à prática educativa. [...] tomar a própria prática de abertura ao outro como objeto da reflexão crítica deveria fazer parte da aventura docente.

O grupo de professoras pesquisado participou ativamente do processo de pesquisa e concluiu, ao fim dos seis encontros, que tinha algo a dizer e a fazer, confirmando o papel fundamental da pesquisa da prática docente como construtora de um professor comprometido com a transformação da práxis.

\section{Em busca de uma práxis transformadora}

A realização da pesquisa-piloto em uma escola privada de Curitiba possibilitou a avaliação dos instrumentos criados e utilizados, bem como as modificações necessárias e pertinentes para atingir o objetivo de identificar a representação profissional e social da professora de educação infantil, possibilitar a formação da professora-pesquisadora e estimular a reflexão, na busca de uma práxis transformadora.

A seguir serão descritas, brevemente, as principais alterações realizadas nos instrumentos a partir dessa primeira experiência na escola.

$\mathrm{Na}$ entrevista das professoras, um terço das questões foi reformulado para tornarem-se mais claras e específicas, a fim de atender os objetivos propostos; acrescentou-se mais um quarto de perguntas para contemplar aspectos da pesquisa que não eram, até então, abordados na entrevista; algumas questões foram excluídas e outras aglutinadas.

Em relação aos diários dos alunos, foi verificada a dificuldade de analisar os desenhos das crianças menores de 4 anos, por estarem na fase da garatuja. Nessa etapa torna-se difícil identificar o significado da expressão gráfica da criança sem o intermédio da linguagem oral infantil e o registro no papel feito pela professora. Dessa forma, optou-se por fazer 
o registro do que a criança desenhou imediatamente após a realização da tarefa. Um aspecto a ser observado nos diários é a existência de relação dos desenhos com as atividades descritas no diário da professora.

Já o diário das professoras possibilitou relacionar o estilo de aprendizagem predominante da docente com o registro feito nos diários, denotando a não correspondência entre os dois aspectos. O total das professoras tem estilo reflexivo predominante, porém somente duas das sete professoras demonstram no registro escrito dos diários aspectos reflexivos e críticos. A partir dessa constatação pergunta-se: será que as professoras apresentam estilo de aprendizagem reflexivo ou gostariam de ter esse estilo por ser o mais valorizado pela cultura contemporânea? A resposta para essa questão suscita a possibilidade de um novo estudo. Além disso, foram criadas categorias para análise dos diários, assim como foi destacada a importância de analisar se há evolução nos três registros do diário das professoras. A orientação escrita da maneira como a professora deve realizar o registro no diário também foi alterada para esclarecer aspectos relevantes a serem realizados pelas professoras, como fazer o registro do diário da professora no mesmo dia da realização do diário do aluno.

Na observação da sala de aula, sentiu-se falta da elaboração de um protocolo que pudesse orientar o olhar do observador pesquisador. Então, esse protocolo de observação foi elaborado.

O questionário construído para os pais sofreu pequenas alterações na maneira de preencher as questões, tornando as respostas mais precisas e objetivas quando eram questões fechadas.

A entrevista realizada com a comunidade educativa (os funcionários) permaneceu sem alterações, assim como o questionário Honey-Alonso.

Em relação ao Inventário Portilho/Beltrami, decidiu-se aplicá-lo com uma amostra significativa de cada sala, juntamente com perguntas metacognitivas e com o acompanhamento de uma das pesquisadoras.

O desenho da professora realizado pelos alunos também contará com a presença de uma pesquisadora que observará a atividade e fará perguntas metacognitivas, com uma amostra significativa de crianças, 
que possibilitem mapear o pensamento da criança no momento em que desenha a professora, a fim de entender que reflexões ela faz sobre seu próprio trabalho.

Os encontros reflexivos e as rodas de conversa presentes nesses encontros caracterizaram-se como momentos possibilitadores de sensibilização para a aplicação dos instrumentos e também de reflexão sobre a prática existente, ressaltando as possíveis mudanças que poderiam ocorrer a partir daquele momento na prática docente, possibilidades de ressignificação da práxis, assim como foram também momentos de elaboração de experiências vividas com alunos, pais e, principalmente, da relação com seus pares. Observou-se que, além de formar os professores nos aspectos relativos a teorias, conteúdos específicos da formação docente, faz parte da formação docente o trabalho com a relação interpessoal, trabalhos em grupo, vivências.

Como afirma Esteban e Zacur,

a prática é o ponto de partida. [...] Dela emergem as questões, as necessidades e as possibilidades [...]. Parte-se da prática para voltar a ela. Porém, na volta, não se encontra a mesma prática inicial, há uma nova qualidade na medida em que o movimento ação-reflexão-ação gera transformações, que permitem avançar em direção à melhor compreensão do fenômeno, relativizando o imediatamente perceptível (ESTEBAN; ZACUR, 2002, p. 21-22).

O trabalho em grupo é fundamental, uma vez que, ao se ter a vivência da situação, tem-se a capacidade de trabalhar com os alunos ou com outros grupos não só a partir da teoria, mas a partir da experiência, integrando-as numa práxis transformadora continuamente, pois, como ensina Freire (2008, p. 39), “[...] na formação permanente dos professores, o momento fundamental é o da reflexão crítica sobre a prática. É pensando criticamente a prática de hoje ou de ontem que se pode melhorar a próxima prática".

A tomada de consciência de que essa melhora na prática é fruto de pesquisa constante e de muito aprofundamento teórico torna aquele que ensina agente transformador da realidade, porque a partir daí é que 
se compromete, inserindo-se nela como sujeito que constata para mudar, e não apenas se adaptar. A mera adaptação é o limite. Já a atitude de busca é aquela que possibilita levar ao êxito porque promove um movimento em direção à transformação da educação.

\section{Agradecimentos}

Aos demais membros da pesquisa:

Prof. Dr. Ricardo Tescarolo, Ana Regina Braga, Arlete Z. Serafini, Beatriz Bruce, Carla C. Tosatto, Giovanna B. K. Medina, Giovani Batista, Isabel Parolin, Kátia Beltrami, Larissa M. Volcov Alves, Laura Monte Serrat Barbosa, Maria Cecília M. N. Giovanella, Maria Gabriela Afonso, Maria Silvia Todeschi de Souza, Marta Moscheto, Mônica C. David, Renata Gueno, Iara Cordeiro, Silvia Martinez, Simone Calberg, Sônia Maria Küster, Thalita Folmann da Silva.

\section{Referências}

BOFF, L. Saber cuidar: ética do humano - compaixão pela terra. 16. ed. Petrópolis: Vozes, 1999.

BRASIL. Ministério da Educação. Plano Nacional de Educação. Brasília: Inep, 2001. BRASIL. Ministério da Educação. Secretaria de Educação Fundamental. Referencial curricular nacional para a educação infantil. Brasília: MEC, 2001.

EDUCAÇÃO. In: HOUAISS, A. Dicionário eletrônico Houaiss da língua portuguesa. 2007. 1 CD-ROM.

ESTEBAN, M. T.; ZACCUR, E. (Org.). Professora-pesquisadora: uma práxis em construção. Belo Horizonte: Autêntica, 2002.

FREIRE, P. Pedagogia da autonomia. São Paulo: Paz e Terra, 2008. 
KRAMER, S. Formação de profissionais de educação infantil: questões e tensões. In: MACHADO, M. L. de A. (Org.). Encontros e desencontros em educação infantil. São Paulo: Cortez, 2002.

KRAMER, S. Profissionais de educação infantil: gestão e formação. São Paulo: Ática, 2005.

MOSCOVICI, S. Representações sociais: investigações em psicologia social. 6. ed. Petrópolis: Vozes, 2009.

NÓVOA, A. (Org.). Os professores e a sua formação. Lisboa: Dom Quixote, 1995.

SPINK, J. P. (Org.). O conhecimento no cotidiano: as representações sociais na perspectiva da psicologia social. São Paulo: Brasiliense, 1995.

Recebido: 12/09/2010

Received: 09/12/2010

Aprovado: 20/11/2010

Approved: 11/20/2010 